\title{
PARQUES TECNOLÓGICOS: ALAVANCAGEM ECONÔMICA DO ENTORNO.
}

\author{
J.Oliveira $^{1 *}$; R.F.Habas ${ }^{1}$; F.M.Bagatini ${ }^{1}$; M.P.Rodrigues ${ }^{1}$ e R. Barrichelo ${ }^{1}$ \\ 1 Universidade Comunitária da Região de Chapecó - UNOCHAPECÓ, 89809-900, Brasil \\ *jhonnyjc@unochapeco.edu.br
}

Artigo submetido em 15/03/2017 e aceito em 07/07/2017

\begin{abstract}
RESUMO
Este artigo apresenta os resultados de uma pesquisa bibliométrica sobre como os parques tecnológicos alavancam a economia ao seu entorno. A partir de análises em relatórios do MCTI, Anprotec, Sebrae e ABDI, foi possível coletar os resultados para esse estudo. Os resultados obtidos sugerem uma contribuição significativa destes ecossistemas, com impactos sociais e econômicos nas regiões onde estão instalados. De acordo com estimativas mostradas pelo MCTI (2014) os parques científicos e tecnológicos do país apresentam um total de 939 empresas, com uma concentração na região Sul $(40 \%)$, Nordeste $(32 \%)$ e Sudeste $(25 \%)$. Estes geraram
\end{abstract}

mais de 32.237 empregos diretos. O estudo da Anprotec/Sebrae (2016) indica que os gastos das empresas incubadas resultam em um total de $\mathrm{R} \$$ 1.299.645.783,17 em renda para outros setores da economia e fomentam um total de 35.777 empregos indiretos, sendo que empresas graduadas geram de $\mathrm{R} \$$ 21.802.099.239,45 na produção nacional e $R \$$ 12.280.929.318,43 na renda, além da geração de 338.071 empregos indiretos, totalizando $\mathrm{R} \$ 24.109 .335 .573,61 \mathrm{na}$ produção nacional, uma renda de $\mathrm{R} \$ 13.580 .575 .101,59$ e 373.847 empregos indiretos.

PALAVRAS-CHAVE: Parques tecnológicos, inovação, empregos qualificados, resultados econômicos

\section{TECHNOLOGICAL PARKS: ECONOMIC LEVERAGE OF THE ENVIRONMENT.}

\begin{abstract}
This paper presents the results of a bibliometric research on how technology parks leverage the economy to their environment. From analyzes in reports of the MCTI, Anprotec, Sebrae and ABDI, it was possible to collect the results for this study. The results suggest a significant contribution of these ecosystems, with social and economic impacts in the regions where they are installed. According to estimates by MCTI (2014), the country's scientific and technological parks have a total of 939 companies, with a concentration in the South (40\%), Northeast $(32 \%)$ and Southeast $(25 \%)$. These generated more than 32,237 direct jobs. The study by Anprotec /
\end{abstract}

Sebrae (2016) indicates that the expenses of the incubated companies result in a total of $R$ \$ $1,299,645,783.17$ in income for other sectors of the economy and foment a total of 35,777 indirect jobs, and that graduated companies generate $\mathrm{R} \$$ $21,802,099,239.45$ in national production and $\mathrm{R} \$$ $12,280,929,318.43$ in income, in addition to the generation of 338,071 indirect jobs, totaling $\mathrm{R} \$$ $24,109,335,573.61$ in national production, an income of R \$ 13,580,575,101, 59 and 373,847 indirect jobs.

KEYWORDS: Technology parks, innovation, skilled jobs, economic results 


\section{INTRODUÇÃO}

Os Parques Tecnológicos afluem interesse de estudos por pesquisadores, empreendedores, instituições, órgãos governamentais e interessados. Diversos países fazem importantes investimentos pelos resultados fascinantes que são gerados. Nas últimas décadas as experiências bem sucedidas em países como Espanha, Finlândia, França, Estados Unidos, Coréia, Taiwan entre outros, chamam a atenção em todo o mundo e estimulando inúmeros empreendimentos do gênero no Brasil.

Os parques tecnológicos proporcionam um ambiente de inovação. Sendo eles grandes agentes no desenvolvimento regional e nacional, onde proporcionam empregos, bem-estar social, além de arrecadação de impostos (STEINER, 2010).

Os resultados econômicos e sociais obtidos com a implantação de Parques Tecnológicos, tanto no Brasil como no mundo, vêm sendo mensurados ao longo das últimas décadas e demonstram claramente uma importante opção para estimular regiões em estagnação ou depressão econômica. A variedade de tecnologias geradas nestes ambientes tem propiciado a sustentabilidade de inúmeros empreendimentos nos mais diferentes setores da atividade econômica.

Os estudos efetuados pelos mais diferentes órgãos como Ministério da Ciência, Tecnologia e Inovação - MCTI, Ministério da Indústria, Comércio Exterior e Serviços - MDIC, Financiadora de Estudos e Projetos - FINEP, Banco Nacional de Desenvolvimento Econômico e Social - BNDES, Centro de Gestão e Estudos Estratégicos - CGEE, Serviço de Apoio às Micros e Pequenas Empresas - SEBRAE entre outros, evidenciam a importância das transformações geradas e possibilitam aos agentes públicos e privados a compreensão da dimensão dos desafios e oportunidades de desenvolvimento econômico social e tecnológico para o País.

$\mathrm{Na}$ direção dos Parques Tecnológicos ocorrem as transformações do seu entorno. As interações geradas possibilitam a atração de investimentos secundários, exigem do poder público a implantação de infraestrutura adequada, estimulam a urbanização e geram mudanças significativas nas suas adjacências. É nesse contexto que o presente estudo pretende responder a seguinte questão: Quais são os resultados originados através dos Parques Tecnológicos (alavancagem econômica do seu entorno)?

Portanto, pretende-se apresentar através deste estudo, a importância dos parques na geração de emprego, na geração de produtos e serviços inovadores, como também, o fomento da economia e o desenvolvimento do país. Os Parques Tecnológicos podem ser compreendidos como instrumentos estratégicos para promover a interação e a cooperação para inovação, pois integram num mesmo ambiente todos os elementos necessários para que a inovação aconteça com maior velocidade e qualidade.

\section{MATERIAIS E MÉTODOS}

Para a realização da presente pesquisa, e tendo em vista os objetivos propostos, primeiramente realizou-se, de abril a julho de 2016, uma análise em 17 artigos publicados na área de Gestão da Inovação, Hélice Tríplice e Parques Tecnológicos, sendo que destes utilizou-se 11 para o estudo. Para o resultado da pesquisa procurou-se, de agosto de 2016 a janeiro de 2017, relatórios e estudos sobre Parques Tecnológicos nas fontes da ANPROTEC, MCTI, e ABDI.

A presente pesquisa analisa as bibliografias disponíveis sobre o assunto, com uma análise sobre o tema, para isso utilizando-se da análise bibliométrica, que segundo Tague-Sutckiffe apud Araújo (2011), pode-se definir a bibliometria como: "o estudo dos aspectos quantitativos da 
produção, disseminação e uso da informação registrada", publicada nos meios científicos e que servirá de referência nos estudos e planejamento de novos Parques no Brasil.

Para buscar uma melhor caracterização da realidade dos parques científicos e tecnológicos brasileiros em seus entornos, a presente pesquisa utilizou-se da combinação de fontes secundárias. Desta forma a pesquisa foi em seu momento orientada pelo levantamento de informações secundárias provenientes de publicações em sites de governos e entidades representativas de parques científicos e tecnológicos. Sendo os dados coletados dos seguintes órgãos: MCTI, Anprotec, Sebrae e ABDI.

Uma vez definidas as variáveis a serem investigadas junto às iniciativas nacionais, a pesquisa composta por aspectos quantitativos e qualitativos, analisou-se dados das diversas iniciativas de parques científicos e tecnológicos do país. São apresentados os principais dados dos Parques Tecnológicos em seu entorno e uma síntese com os resultados adquiridos.

\section{REVISÃO DE LITERATURA}

\subsection{Gestão da Tecnologia e Inovação}

A inovação é dirigida pela habilidade de ver conexões, de detectar oportunidades e tirar vantagens delas, não se refere apenas a produtos, mas também a serviços tanto no público como no privado. No contexto atual onde passamos por grandes mudanças socioeconômicas, ambientais, políticas, entre outras, as empresas bem-sucedidas são aquelas que inovam e essa vantagem advém da capacidade organizacional em mobilizar conhecimento, habilidades tecnológicas e experiência para criar novidades em suas ofertas (produtos/serviços) e nas formas que criam e entregam essas ofertas (TIDD; BESSANT; PAVITT, 2000).

As empresas inovam para a melhoria de seu desempenho, um novo produto ou processo pode ser uma fonte de vantagem mercadológica para o inovador. No caso de inovações de processo que aumentam a produtividade, a empresa adquire uma vantagem de custo sobre seus competidores; no caso da inovação de produto, a empresa pode ganhar uma vantagem competitiva por meio da introdução de um novo produto, o que lhe confere a possibilidade de maior demanda e maior margem sobre custos (MANUAL DE OSLO, 2011).

Num mundo em que o ciclo de vida dos produtos é cada vez menor, a capacidade de substituir produtos por versões mais modernas com frequência é cada vez mais importante. Competir com o tempo reflete uma crescente pressão sobre as empresas, não somente para introduzir novos produtos no mercado, como também para fazer isso mais rápido que seus concorrentes (TIDD; BESSANT; PAVITT, 2008).

De acordo com o Manual de Oslo (2011), uma organização pode realizar vários tipos de inovação em seus métodos de trabalho, seu uso de fatores de produção e os tipos de resultados que aumentam sua produtividade e/ou seu desempenho comercial. Existem quatro tipos de inovações que encerram um amplo conjunto de mudanças nas atividades das empresas, sendo elas: inovações de produto, processo, organizacionais e inovações de marketing.

As organizações percebem que uma das características mais importantes é a inovação, muitas a consideram como a que mantém a empresa viva e competitiva. Para Vico Manãs (2001, p. 21) "a inovação calcada no conhecimento pode levar as organizações a garantias de 'menos riscos'. Basear-se em conhecimento, significa ter 'o saber' da duração, taxa de perdas, predicabilidade e os desafios que lhe apresentam". 
Entretanto, Tigre (2012) define a tecnologia como o conhecimento sobre técnica, sendo que as técnicas envolvem aplicação do conhecimento em produtos, processos e métodos organizacionais, gerando a inovação. Muitas invenções surgiram da experimentação prática da combinação de tecnologias já existentes, visando criar valor a um negócio.

Dessa forma Vico Manãs (2001) enfatiza que a inovação tecnológica deve ser planejada e paralelamente permitir e colaborar com um esforço por procuras de alternativas para solucionar e melhorar a vida, o trabalho, e tudo o mais envolvido no processo.

\subsection{Hélice Tríplice}

O termo Hélice Tríplice foi criado por Henry Etzkovitz nos anos 90 com o objetivo de descrever o modelo de inovação com base na relação entre as instituições Governo-Universidade e Empresa (ETZKOWITZ, 1994 apud GOMES, PEREIRA, 2015). Trata-se de um modelo circular de inovação que leva em consideração as múltiplas relações mútuas em diferentes estágios do processo de geração e disseminação do conhecimento (GOMES, PEREIRA, 2015).

A Hélice Tríplice une a articulação entre Governo e Empresa, com grande participação da Universidade, ela estabelece-se como uma mola propulsora para o desenvolvimento econômico e social (CRUZ et al., 2013).

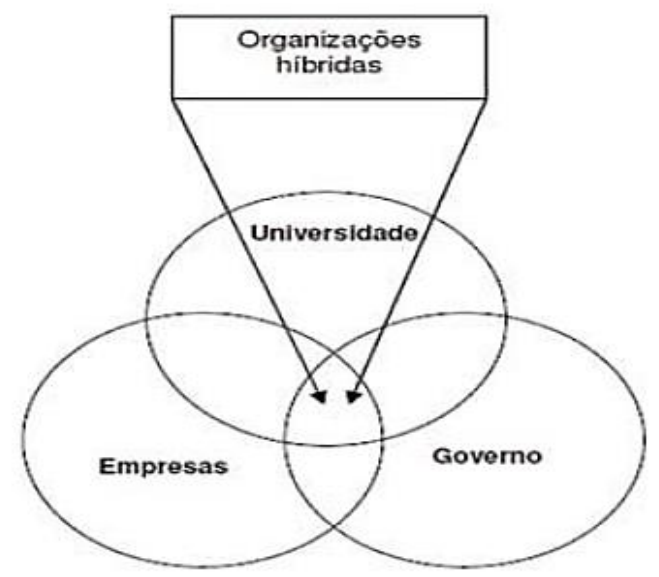

Figura 1. Hélice Tríplice Universidade-Empresa-Governo

Fonte: adaptado de Etzkowitz, Leydesdorff ,2000 apud Cruz et al., 2013.

O modelo Hélice Tríplice caracteriza as relações entre o Governo, a Universidade e a Empresa e descreve e apresenta como pode ser criado um ambiente propício para a inovação, tornando a geração e a difusão do conhecimento inerente para o desenvolvimento da Sociedade (CLOSS; FERREIRA, 2010 apud GOMES; PEREIRA 2015).

A ordem da Tríplice Hélice tem-se mostrado uma estratégia inovadora, com a finalidade de propor e operacionalizar a implementação de políticas públicas de desenvolvimento regional, alicerçadas no desenvolvimento científico e tecnológico, com vistas a gerar um desenvolvimento auto sustentável suportado através da interação entre os atores das três hélices (CRUZ et al., 2013).

O governo é o responsável por fomentar políticas públicas que incentivem o processo de inovação, bem como por grande parte do financiamento necessário a realização de pesquisas. $\mathrm{O}$ 
governo precisa formular leis e políticas que incentivem o processo de cooperação, pois, na união da Tríplice Hélice o governo assume um papel preponderante no estímulo e implementação de ações e leis, bem como na criação de mecanismos considerados fundamentais ao processo de cooperação (MOTA 1999 apud GOMES; COELHO; GONÇALO, 2014).

A Tríplice Hélice é a chave para a inovação em sociedade baseada cada vez mais no conhecimento. Uma vez que a criação, disseminação e utilização do conhecimento se movem a partir dos arredores para o centro da governança e produção industrial, o conceito de inovação, em produtos e processos, está sendo, ele próprio, transformado (ETZKOWITZ, 2009 apud CRUZ et al., 2013).

\subsection{Parques Tecnológicos}

Os Parques Tecnológicos surgiram nos Estados Unidos na década de 1950, em Stanford, Califórnia (Cooper, 1971 apud MCTI 2013). Baseados na interação entre a universidade e a iniciativa privada, os parques tecnológicos têm por objetivo promover uma infraestrutura técnica, logística e administrativa para ajudar pequenas empresas a desenvolver seus produtos, aumentar a competitividade, favorecer a transferência tecnológica e a criação de um ambiente propício à inovação (Philimore, 1999; Bakouros, Mardas e Varsakelis, 2002 apud MCTI 2013).

Segundo Horácio (2008), os parques tecnológicos são instituições híbridas e de cunho científico e tecnológico, se convertem em espaços que recebem ao mesmo tempo empresas inovadoras, direcionadas pela lógica de mercado e possuem missões relacionadas à educação e produção do conhecimento científico.

No Brasil os Parques Tecnológicos tiveram incentivos na década de 1980, com a criação do Programa Brasileiro de Parques Tecnológicos, pelo Conselho Nacional de Desenvolvimento Científico e Tecnológico - CNPq, visando modificar a realidade econômica do país (MCTI, 2013).

O Ministério de Ciência Tecnologia e Inovação - MCTI, por meio do Programa Nacional de Apoio às Incubadoras de Empresas e Parques Tecnológicos - PNI tem fomentado o surgimento e a consolidação de Incubadoras de Empresas e Parques Tecnológicos, a fim de ampliar e otimizar a geração e consolidação de micro e pequenas empresas inovadoras (MCTI, 2015).

De acordo com a Agência Brasileira de Desenvolvimento Industrial - ABDI, os Parques Tecnológicos são considerados como complexos de desenvolvimento econômico e tecnológico, que visam fomentar economias baseadas no conhecimento por meio da integração da pesquisa científica-tecnológica. Os parques tecnológicos podem abrigar centros para pesquisa científica, desenvolvimento tecnológico, inovação e incubação, treinamento, prospecção, como também infraestrutura para feiras, exposições e desenvolvimento mercadológico (ABDI, 2007).

Entretanto, são considerados como extensão de uma universidade, onde são construídos em uma área próxima da instituição de ensino superior, que possuem instalações de incubadoras de empresas, ligando serviços e negócios, com vistas à inovação, e fundamentados em pesquisas tecnológicas (EUROPEAN COMMISSION, 2007 apud AMARAL, 2014).

O MCTI (2013) destaca que os Parques Tecnológicos são ambientes propícios para promover a interação de instituições e empresas públicas e privadas com a comunidade científica. Nesse contexto, os parques tecnológicos são apontados como ecossistemas com alto potencial para romper a lógica existente hoje no país de não se conseguir transformar o conhecimento científico em desenvolvimento social e econômico. O reconhecimento desse potencial fez com que o Governo Federal desse início, há pouco mais de vinte anos, a um processo consistente de definição de 
políticas públicas e de investimentos financeiros visando à criação e à consolidação de parques tecnológicos em todas as regiões do país.

Os Parques Tecnológicos, caracterizam-se como empreendimentos imobiliários de impacto, que repercutem redes urbana e ambiental nas quais eles se inserem (HAUSER, 1997; BERMÚDEZ, SPOLIDORO, 1997).

Os Parques Tecnológicos proporcionam aos empreendimentos infraestrutura física, telecomunicação, transporte, recursos humanos e ambiente favorável para habitação, e dentre os quais se destacam: Transferência de tecnologia de universidades ou centros de pesquisa para empresas inovadoras; Incubação de negócios baseados em conhecimento, oferecendo aos empreendedores expertise em gestão, acesso a financiamento, network de negócios e ferramentas necessárias para o sucesso do empreendimento. Os parques científicos e tecnológicos podem se consolidar, de fato, como grandes plataformas para promoção do desenvolvimento de regiões e setores, estabelecendo oportunidades diferenciadas para o direcionamento do processo de crescimento (ABDI, 2007).

\section{RESULTADOS E DISCUSSÃO}

Esta pesquisa apresenta dados disponíveis por órgãos que estimulam a inovação através da implantação de Parques Científicos e Tecnológicos, sendo eles: Ministério da Ciência Tecnologia e Inovação-MCTI, Associação Nacional de Entidades Promotoras de Empreendimentos InovadoresANPROTEC, Agência Brasileira de Desenvolvimento Industrial-ABDI, e Serviço de Apoio às Micro e Pequenas Empresas - SEBRAE. Por meio dos resultados pode-se notar a importância dos parques na geração de emprego, na geração de produtos e serviços inovadores, como também, o fomento da economia e o desenvolvimento do país.

O incentivo à inovação tecnológica é uma forma de promover o desenvolvimento do País. Países desenvolvidos compreendem que é por meio do desenvolvimento tecnológico que é possível criar novas empresas com empregos qualificados, que desenvolvem produtos inovadores, isso gera riqueza e desenvolvimento para o País. Os Parques Tecnológicos podem ser percebidos como instrumentos estratégicos para promover a interação e a cooperação para inovação, pois integram num mesmo ambiente todos os elementos necessários para que a inovação aconteça com maior velocidade e qualidade.

Segundo o Manual de Oslo (2005) inovação é a implementação de um produto, bem ou serviço, novo ou com um alto melhoramento do mesmo, ou um processo, ou um novo método de marketing, ou um novo método organizacional nas práticas de negócio, na organização do local de trabalho ou nas relações externas.

De acordo com o MCTI (2015), um dos diferenciais que um Parque Tecnológico oferece é a gestão da inovação, atraindo e integrando seus elementos para operacionalização de projetos mobilizadores que possam dinamizar o desenvolvimento de uma região, apoiando a organização dos clusters locais e, consequentemente, gerando maior agregação de valor nas cadeias produtivas.

Os Parques Tecnológicos e as Incubadoras de Empresas são mecanismos fundamentais para uma política integrada de desenvolvimento e inovação no Brasil. As incubadoras têm se mostrado como excelentes instrumentos para promover o empreendedorismo e gerar empresas com novas tecnologias e produtos inovadores (MCTI, 2015).

O incentivo a inovação passou a ser umas das prioridades do governo, no incentivo da geração de parques tecnológicos e incubadoras tecnológicas. Essas ajudam no desenvolvimento do 
país através da geração de emprego e no desenvolvimento de produtos e serviços inovadores com novas tecnologias.

Na Figura 2 é possível observar a importância de uma combinação de esforços, tanto públicos quanto privados, para a viabilização desses instrumentos. Esta combinação é essencial para o desenvolvimento dos parques tecnológicos.

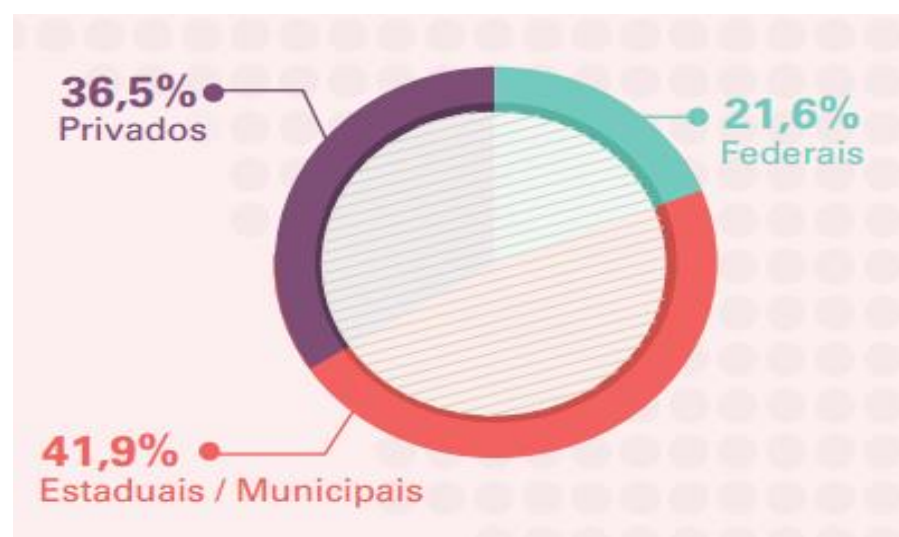

Figura 2. Distribuição das fontes de recursos dos parques Fonte: MCTI, p. 39, 2014.

De acordo com estimativas apresentadas pelo MCTI (2014) os parques científicos e tecnológicos do país apresentam um total de 939 empresas, com uma concentração na região Sul (40\%), Nordeste (32\%) e Sudeste (25\%). As regiões Centro-Oeste e Norte congregam somente 3\% das empresas. A Figura 3 apresenta a quantidade de empresas instaladas nos parques tecnológicos, distribuídas pelas cinco regiões brasileiras.

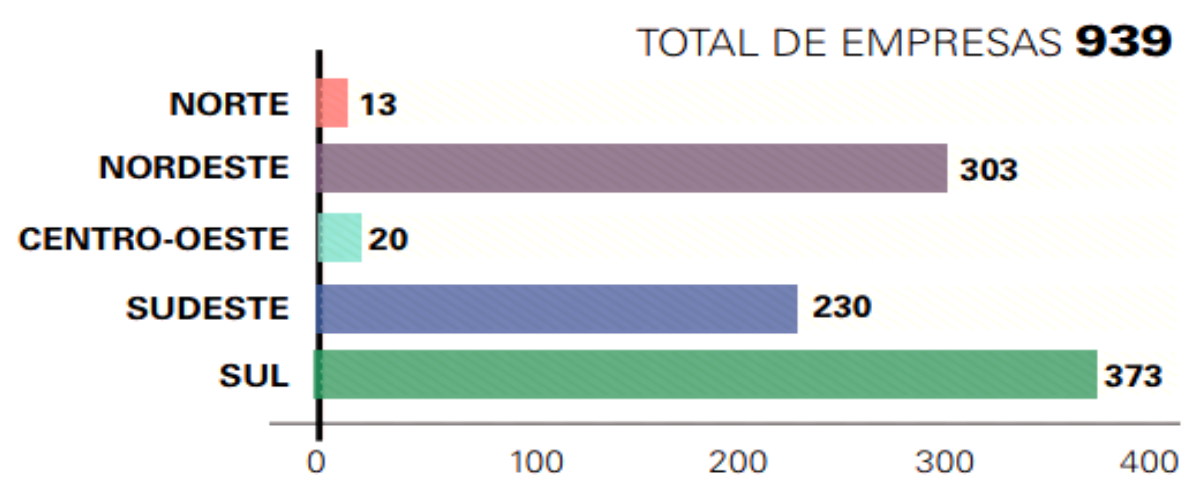

Figura 3. Número de empresas por parques Fonte: MCTI, p. 31, 2014.

Nota-se que a região Sul apresenta uma maior quantidade de empresas instaladas nos Parques Tecnológicos. Estas empresas, conforme observado por Steiner (2010), geram empregos de qualidade e colaboram para a economia das regiões onde estão inseridas. 


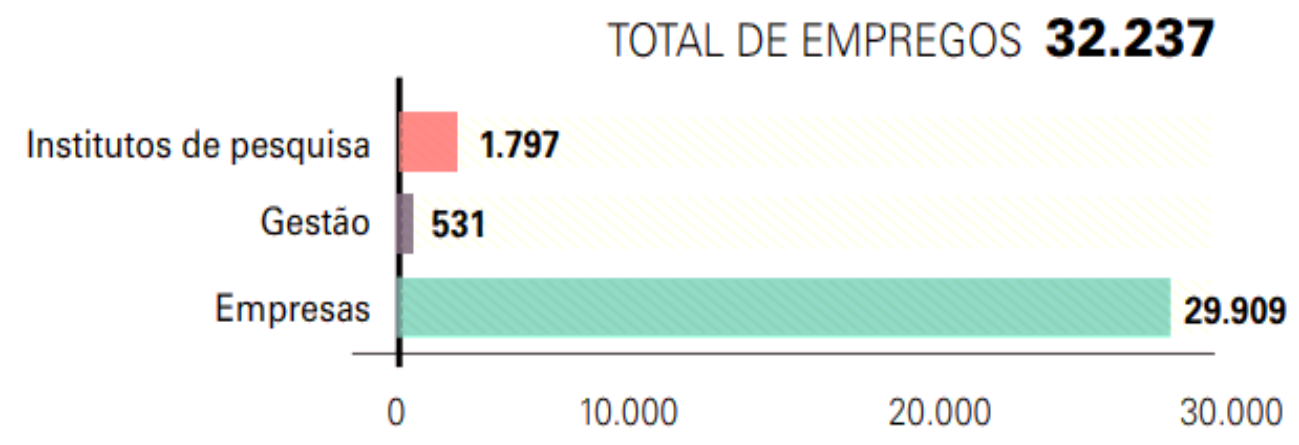

Figura 4. Número de empregos nos parques

Fonte: MCTI, p.32, 2014.

Dos 29.909 empregos gerados pelas empresas instaladas nos parques, segundo os indicadores de parques tecnológicos, produzido pelo MCTI (2015), 3,7\% são ocupados por profissionais que possuem o título de doutor, $9,9 \%$ por profissionais com titulação de mestre, 7,9\% por diplomados em cursos de especialização e 58,9\% por diplomados com formação máxima em nível superior, totalizando $70,5 \%$ de profissionais com formação superior completa atuando nestes espaços.

É importante considerar que a produtividade da mão-de-obra de empresas intensivas em tecnologia é naturalmente mais elevada. Segundo estudos recentes da OCDE9, cerca de 50\% a 70\% do incremento de produtividade nos últimos 10 anos se deve ao setor de "Serviços de negócios" excluindo serviços de corretagem.

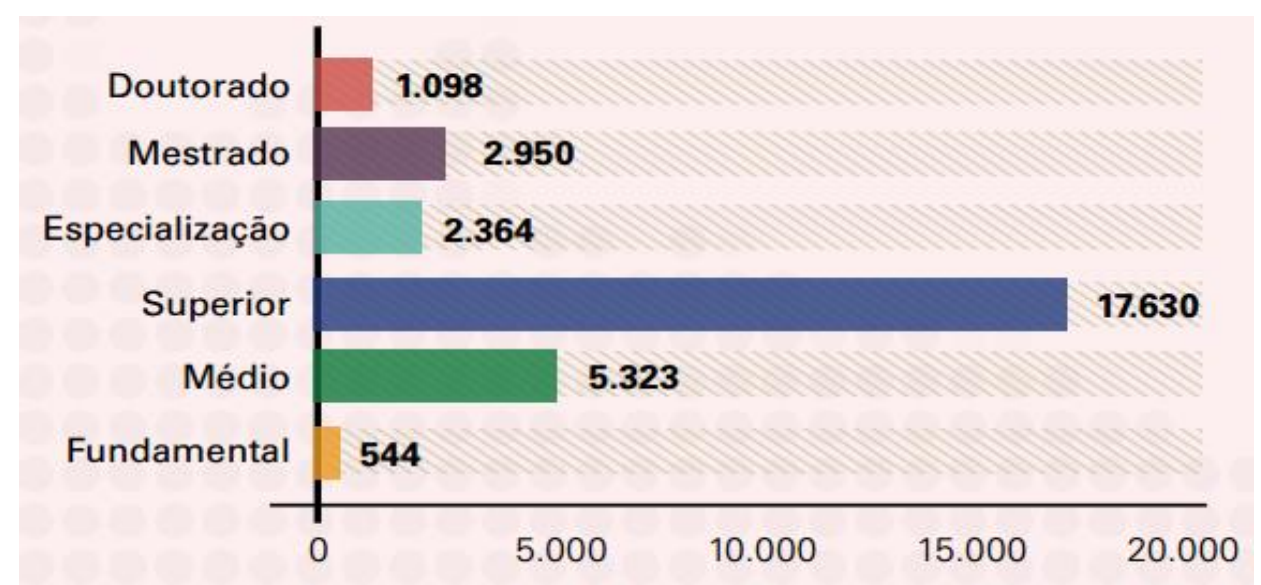

Figura 5. Número de empregos nas empresas por nível de qualificação Fonte: MCTI, p.33, 2014.

Ao analisar as Figuras 3, 4 e 5 percebe-se que, conforme MCTI (2015) dentro do contexto da tripla hélice, a proximidade dos parques com institutos de pesquisa e universidades e os incentivos governamentais na promoção desses como ambientes de inovação, têm propiciado aos setores público e privado um ambiente favorável ao desenvolvimento de inovações e a melhoria da competitividade de seus produtos, processos e serviços. 
Conforme estudo de impacto econômico, Anprotec/Sebrae (2016), o faturamento estimado das empresas incubadas e graduadas, que representam o impacto direto das atividades das empresas desse segmento na economia do Brasil é de R \$ 15.259.073.147,86, sendo R \$ 1.460.276.160,86 o impacto direto das 2.310 empresas incubadas e $\mathrm{R} \$ 13.798 .796 .987,00$ das 2.815 graduadas. Desse valor, $\mathrm{R} \$$ 8.876.202.850, 11 é transformado em renda na economia, gerando um total de 53.280 empregos diretos, sendo 15.477 oriundos das empresas incubadas e 37.803 das empresas graduadas. Esses dados podem ser observados na Figura 6.

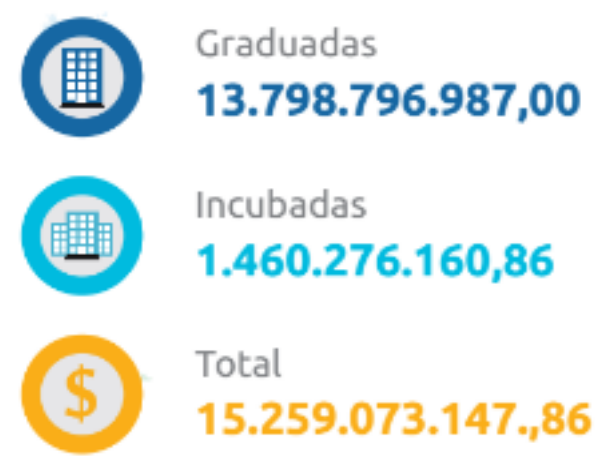

Figura 6. Impactos diretos das empresas incubadas e graduadas em R\$ Fonte: Anprotec/Sebrae, p. 18, 2016.

A Figura 7 apresenta os gastos que as empresas incubadas geram, conforme Anprotec/Sebrae (2016) ainda, um total de $\mathrm{R} \$ 1.299 .645 .783,17$ em renda para outros setores da economia e geram um total de 35.777 empregos indiretos.

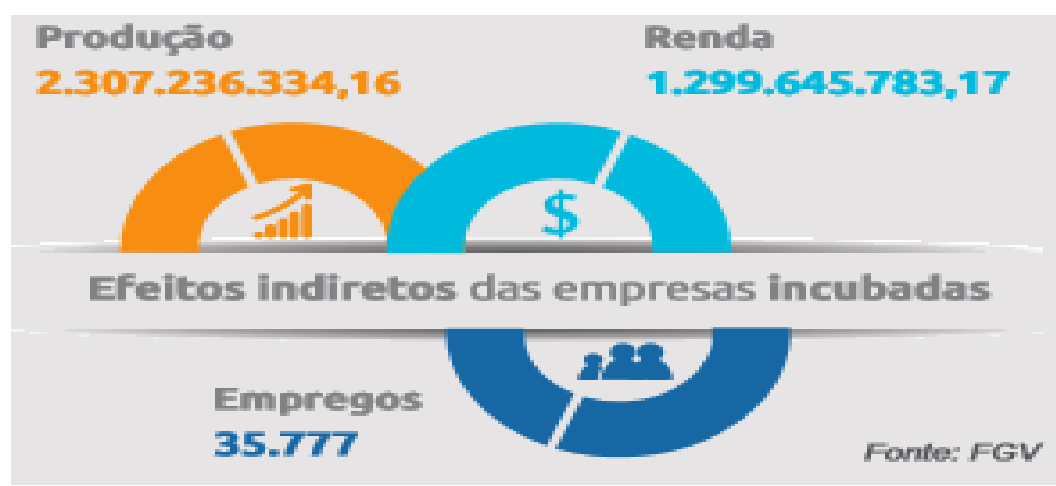

Figura 7. Efeitos indiretos das empresas incubadas Fonte: Anprotec/Sebrae, p. 19, 2016.

Da mesma forma que as empresas incubadas, as empresas graduadas geram efeitos indireto na economia nacional. O impacto indireto, conforme Figura 8 é de R\$ 21.802.099.239,45 na produção nacional e $\mathrm{R} \$ 12.280 .929 .318,43$ na renda, além da geração de 338.071 empregos indiretos. 


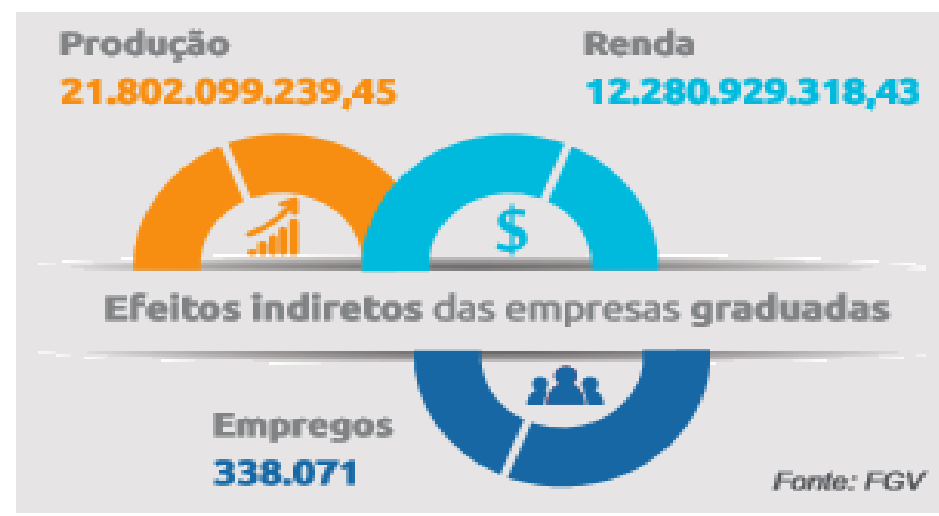

Figura 8. Efeitos indiretos das empresas graduadas Fonte: Anprotec/Sebrae, p. 19, 2016.

As estratégias para o aumento da competitividade econômica das nações surgem intimamente atreladas ao desenvolvimento de inovações. A construção de um ambiente propício ao investimento em inovação no país foi beneficiada não apenas por iniciativas como o Plano Brasil Maior (PBM), os INCT, o Plano Inova Empresa, o Sistema Brasileiro de Tecnologia (Sibratec) e a nova Empresa Brasileira de Pesquisa e Inovação Industrial (Embrapii), mas também pela implementação de um mecanismo legal e institucional para a comercialização e colaboração em PD\&I entre universidades e indústria.

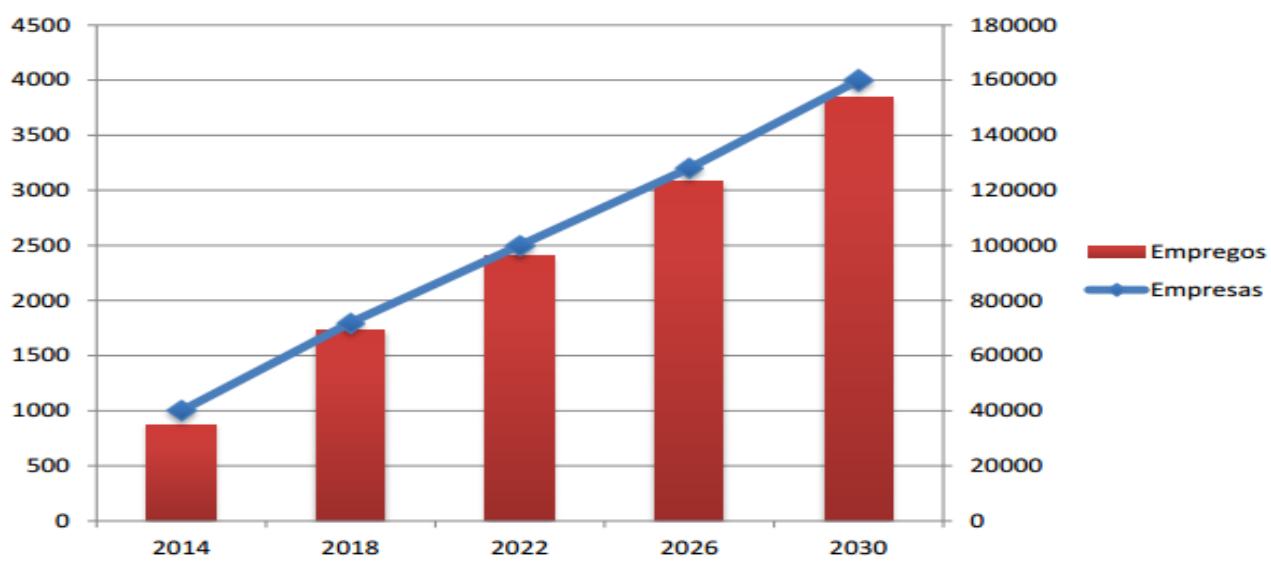

Figura 9. Projeções de empresas e empregos nos Parques Tecnológicos Fonte: MCTI, (pg. 43, 2015).

Estes ambientes que foram incentivados no Brasil a partir da década de 1980, segundo projeções do MCTI, até 2030 tendem a quadruplicar o número de empresas e empregos que podem contribuir ainda mais no desenvolvimento social e econômico de diversas regiões do país.

\section{CONCLUSÃO}

Este artigo apresentou os resultados de uma pesquisa bibliométrica que teve por finalidade tratar sobre como os parques tecnológicos alavancam a economia ao seu entorno, na geração de empregos, de produtos e serviços, como também, para o fomento da economia e o desenvolvimento do país, sendo que os dados apresentados foram coletados dos seguintes órgãos: MCTI, Anprotec, Sebrae e ABDI. 
A partir do estudo realizado é possível identificar que o estímulo à inovação, a partir da aproximação de diferentes agentes, que com políticas, investimento financeiro e conhecimento aplicado, estimulam a inovação através da implantação de Parques Científicos e Tecnológicos.

Dessa forma, para transformar conhecimento e ciência em riqueza e negócios inovadores, com agregação de valor em produtos e serviços, torna-se essencial o apoio institucional e financeiro das três diferentes esferas, universidade pública e privada, bem como a articulação com as políticas públicas de desenvolvimento regional.

Os impactos sociais e econômicos nas regiões onde o sistema dos parques tecnológicos está inserido, é percebido pelos resultados de empregos, diretos ou indiretos, e receitas geradas no entorno deste ambiente.

\section{REFERENCIAS}

ABDI. Projeto Parques Tecnológicos no Brasil Estudo, Análise e Proposições. Abril, 2007.

AMARAL, Roberto Rogério do. A arquitetura da liderança nos Parques Científicos e Tecnológicos da Catalunha: uma abordagem estratégica / Roberto Rogério do Amaral; orientador, Cristiano José Castro de Almeida Cunha; coorientador, Francisco Antonio Pereira Fialho. - Florianópolis, SC, 2014.

ANPROTEC. Estudo de impacto econômico: segmento de incubadoras de empresas do Brasil / Associação Nacional de Entidades Promotoras de Empreendimentos Inovadores. - Brasília, DF : ANPROTEC : SEBRAE, 2016.

ARAÚJO, Ronaldo Ferreira. A bibliometria na pesquisa científica da pós graduação brasileira de 1987 a 2007. R. Eletr. Bibliotecon. Florianópolis, v. 16, n. 31, p.51-70, 2011.

BERMÚDEZ, L. A. SPOLIDORO (1997), R. A Sociedade do Conhecimento e seus impactos no meio urbano. In: PALADINO, G. G. MEDEIROS, L. A. (org.) Parques Tecnológicos e Meio Urbano: Artigos e Debates. Brasília: ANPROTEC, 1997

CRUZ, Franciane Cougo da; et al. Tríplice Hélice na região da campanha: um ensaio teórico como fator estratégico de inovação e desenvolvimento. FACEF Pesquisa: Desenvolvimento e Gestão, v.16, n.3 - p.281-300 - set/out/nov/dez 2013.

GOMES, Myller Augusto Santos; COELHO, Tainá Terezinha; GONÇALO, Cláudio Reis. Tríplice Hélice: a Relação Universidade-Empresa em Busca da Inovação. Revista Gestão.Org, v. 12, n. 1, 2014.

GOMES, Myller Augusto Santos; PEREIRA, Fernando Eduardo Canziani. Hélice Tríplice: um ensaio teórico sobre a relação universidade-empresa-governo em busca da inovação. Int. J. Knowl. Eng. Manage., ISSN 2316-6517, Florianópolis, v.4, n.8, p.136-155, mar/jun. 2015.

HAUSER, G. Parques Tecnológicos e Meio Urbano. In: PALADINO, G. G.; MEDEIROS, L. A. (org.). Parques Tecnológicos e Meio Urbano: artigos e debates. Brasília: ANPROTEC, 1997.

HORÁCIO, F.. O Desafio de Implantar Parques Tecnológicos, 2008. Disponível em: http://www.anprotec.org.br/Relata/ArtigosCompletos/ID\%20143.pdf

Delimitando_o_framework_de_implantacao_de_parques_tecnologicos_parte4.pdf. Acessado em julho de 2016.

MANUAL DE OSLO. Diretrizes para coleta e interpretação de dados sobre inovação.3 ed. Finep, 2005. http://www.finep.gov.br/images/apoio-e-financiamento/manualoslo.pdf Acessado em julho de 2016.

MCTI. Estudo de Projetos de Alta Complexidade: indicadores de parques tecnológicos / Centro de Apoio ao Desenvolvimento Tecnológico. Ministério da Ciência, Tecnologia e Inovação - Brasilia: CDT/UnB, 2013.

MCTI. Parques \& Incubadoras para o desenvolvimento do Brasil: Estudo de Práticas de Parques Tecnológicos e Incubadoras de Empresas / Ministério de Ciência, Tecnologia e Inovação - MCTI ; - Brasília : MCTI, 2015. 
Parques \& Incubadoras para o Desenvolvimento do Brasil : Propostas de Políticas públicas para Parques Tecnológicos e Incubadoras de Empresas/ Ministério de Ciência, Tecnologia e Inovação - MCTI ; - Brasília : MCTI, 2015.

STEINER, J. E., CASSIM, M. B., ROBAZZI, A. C. Parques Tecnológicos: Ambientes de Inovação. Disponível em: http://www.iea.usp.br/publicacoes/textos/steinercassimrobazziparquestec.pdf. Acesso em: julho de 2016.

TIDD Joe; BESSANT John; PAVITT Keith. Gestão da inovação. Tradução Elizamari Rodrigues Becker... [et al].- 3. ed. -Porto Alegre : Bookman, 2008.

VICO MAÑAS, A. Gestão de Tecnologia e Inovação. 3 ed. rev. atual. São Paulo. Érica, 2001. 